\title{
O GÊNERO EM DISPUTA: AUSÊNCIAS E PRESENÇAS DA DEMANDA LGBT NA ESCOLA
}

\author{
Rafael Lima Vieira \\ Universidade do Minho, Braga, Portugal \\ Allene Carvalho Lage \\ Universidade Federal de Pernambuco (UFPE), Recife, Pernambuco, \\ Brasil
}

RESUMO: Este artigo apresenta a questão LGBT e suas demandas à educação como tema central. Objetiva apontar as ausências, assim como as presenças de temas relacionados a gênero no campo educacional, os quais são caros e objeto de disputa à cidadania LGBT.Traz a experiência de pesquisa realizada em cinco municípios do Agreste Pernambuco na tentativa de identificar tais ausências e presenças. Adotou uma metodologia de pesquisa qualitativa, e como estratégia de coleta de dados fez uso de entrevistas semiestruturadas e formulários. Os resultados apontam para o alinhamento das experiências escolares às nossas premissas teóricas no que dizem respeito às políticas educacionais, práticas escolares e representação docente; mas fazem emergir informações importantes e originais nascidas das particularidades de cada contexto analisado.

Palavras-Chave: Escola. Gênero. Disputas políticas. Invisibilidade e representação LGBT. 


\section{INTRODUÇÃO}

Caminhando na direção de analisar a suposta invisibilidade da relação entre a população LGBT e a escola, nos deparamos com um contexto em que se torna impossível negar que as instituições escolares, principalmente por mérito da comunidade estudantil, têm se mesclado de identidades dissidentes de gênero, ou seja, que fogem a padrões historicamente estabelecidos a essa categoria (COLLING, 2015). Essas gerações, que têm desconstruído a noção de heteronormatividade, têm feito emergir na escola incômodos de várias modalidades e intensidades. Tais incômodos não se dão pela percepção de que essas modalidades estão deslocadas da normatização clássica dos gêneros; eles acontecem, sobretudo, na alarmante evidência de que o mundo caminha para a experimentação de novas formas de viver o gênero e a sexualidade e de que as performances sexuais e de gênero ortodoxas estão obsoletas e gradativamente caindo em desuso. As dissidências de gênero são, portanto, escandalosas.

Não existe, então, nada de silencioso nas experiências das dissidências sexuais e de gênero. As dinâmicas de silenciamento, no máximo, imprimem ao ambiente em que elas circulam - e aqui nos referimos especificamente aos espaços escolares - sintomas de uma neurose doentia que se manifesta através de uma violenta repressão e interdição, algumas vezes bem sucedidas.

Nota-se, nesse ínterim, uma relação de paradoxal existência de presenças e de ausências elementares no que diz respeito ao aparato institucional e subjetivo que pode fazer da escola terreno de performances de gênero transgressoras. Nesse sentido, a categoria de gênero tem sido uma categoria em disputa nas instituições escolares; e isso fica claro ao observarmos as estratégias de manutenção e ruptura das históricas categorizações identitárias em que o gênero é protagonista.

Face a esta reflexão, esse trabalho argumenta sobre uma questão primeira: como a emergência da população LGBT tem colocado em disputa a categoria de gênero, uma vez que mobiliza fenômenos de produção de visibilidade e invisibilidade na escola?

\section{Metodologia do trabalho}

Este trabalho foi realizado de maneira a inferir sobre dados reais, a partir de pesquisa de campo. Escolhemos para sujeitos de nossa investigação 25 docentes de cinco municípios que abrangem a região do Agreste de Pernambuco, a saber: Belo Jardim, Brejo da Madre de Deus, Caruaru, Pesqueira 
e Santa Cruz do Capibaribe. É importante ressaltar que as escolas em que atuam os sujeitos de nossa pesquisa são pertencentes à rede estadual de ensino.

Buscamos informações no escopo do universo escolar, seja em dados no campo empírico, através das entrevistas, seja em literatura pertinente à educação com relação às categorias de gênero e sexualidade; e ainda apoio em documentos legais sobre a temática. Fizemos uso, como instrumentos de coleta de dados, de entrevistas semiestruturadas e questionários abertos direcionados a docentes das escolas pesquisadas.

Para esta pesquisa utilizamos a Análise de Conteúdo como técnica de análise de dados, que se caracteriza como uma técnica de tratamento da informação. Utilizamo-nos, especificamente, das instruções acerca da análise categorial (BARDIN, 2001). Para esse procedimento preestabelecemos as categorias teóricas que nos ajudassem a categorizar as informações encontradas no campo de investigação. Elegemos as seguintes categorias teóricas para analisar nossos dados: $i$. Política educacional e curricular. ii. Linguagem das práticas escolares. iii. Representação de gênero entre docentes.

Nossa experiência no campo da educação mostra que, convergente com a literatura explorada, essas categorias de análise elegidas ilustram os lugares simbólicos e materiais em que o gênero tem sido disputado. A seguir faremos uma apresentação de como esses elementos mobilizam a categoria de gênero de maneira a dar visibilidade e/ou invisibilidade.

\section{AUSÊNCIAS}

Nessa direção, dialogamos com bases teóricas que apontam para as formas de tensionamento da categoria de gênero no universo da escola e da educação de uma maneira geral. Tentamos aprofundar o debate acerca da disputa da categoria de gênero em nível curricular, político, legal e social, acreditando que podem ser instrumentos básicos para a construção do pensamento sobre o qual nos dispomos a estudar. Dividimos nosso quadro teórico seguindo as exigências de resposta a nosso problema principal.

\section{Política educacional}

Falar de uma política educacional que considere as demandas de gênero da população LGBT é um trabalho exaustivo e infrutífero no Brasil, uma vez que desconhecemos no nível oficial uma resposta do poder público a essa questão. Antes de tudo, consideramos que a consolidação de uma tal política compreende a necessidade de empoderamento de toda a classe profissional e todos os setores envolvidos no processo escolar, principalmente 
daquelas subjetividades que têm lugar de fala e são sujeitos que sofrem com a ausência da mesma (FURLANI, 2005). A implicação da tomada dessa política nas escolas, vista como parâmetro nascido das exigências sociais reivindicadas por tais subjetividades, tem consequências imediatas na sociedade. $\mathrm{O}$ estímulo à violência e à homofobia que perpassa todos os espaços vivenciados pelas identidades LGBT é eco, na maioria das vezes, de práticas nascidas dentro do ambiente escolar, que coloca em circulação um aparato discursivo a serviço da segmentação de ideias equivocadas acerca das noções de gênero e sexualidade.

Além das práticas discursivas, chama-nos a atenção, como contributo à manutenção da situação de silenciamento a que são submetidos esses sujeitos, a ocultação ideológica nos currículos escolares e a orientação política de um projeto de sociedade que desconsidera a esfera das identidades de gênero e das sexualidades. Jimena Furlani alerta para

[...] o ocultamento nos currículos escolares, da multiplicidade das diferenças culturais (em especial dos gêneros e das sexualidades), bem como o não-reconhecimento pedagógico do caráter construído e político das identidades (hegemônicas e subordinadas) e de seus sujeitos. (FURLANI, 2005, p. 220).

Essa afirmação nos coloca, enquanto profissionais da Educação, com um problema de caráter duplo. Primeiro, a escassez de diretrizes curriculares que estabeleçam o trabalho pedagógico voltado à discussão sobre diversidade sexual. Essa questão se torna grave no sentido em que se reconhece não a inexistência de tais diretrizes, mas a contrariedade, de se estabelecer oficialmente, essas diretrizes, visto que grupos de movimentos sociais LGBT, estudiosos da área e organizações não governamentais já têm construídos planos de trabalho pedagógico sobre a temática de gênero demandada pela população LGBT.

Segundo, a lentidão da emergência de estudos sobre o caráter cultural da construção das identidades sexuais, e de sua adesão pelas instituições escolares. Pois apesar de os estudos sobre gênero e sexualidade estarem bem fundamentados e existirem referências para tratar dessa questão em todos os níveis e modalidades de ensino, a escola tem ido contra essa corrente de pensamento, e permanece reproduzindo noções conservadoras sobre gênero e sexualidade. Aqui, a introdução do tema nos currículos, além de acontecer por meio das ocultações dos discursos escolares, legislações e regulamentações, ganha fôlego nas abordagens que têm gênese nos posicionamentos de valores pessoais, morais e religiosos. 
Neste sentido, as inferências sobre esse caráter duplo ganham força quando nos confrontamos com os documentos oficiais que instituem a política educacional brasileira. O que temos observado na atualidade é o alinhamento das políticas de educação com as premissas do direito e da meritocracia, em que a educação está a serviço do atendimento a classes específicas e se dobra às exigências da criação de mão de obra qualificada para o mercado de trabalho, desconsiderando a noção de justiça social; além do patente silenciamento de questões relacionadas a gênero e sexualidade, como está bem ilustrado no Plano Nacional da Educação 2014/2024 brasileiro (BRASIL 2014a, 2014b).

A Base Nacional Comum Curricular (BNCC), proposta que substituiria os Parâmetros Curriculares Nacionais (BRASIL, 1998), que ainda são o principal texto de orientação curricular no Brasil, se caracteriza por estar isenta de referência à diversidade sexual e de gênero no sentido atribuído a ela pelas demandas da população LGBT.

\section{LINGUAGEM DAS PRÁTICAS ESCOLARES}

Temos, hoje, uma forte ligação social entre a linguagem e os meios de comunicação. É quase que impossível desvincular informação e comunicação de termos como "internet", "microcomputador", "televisão", entre outros.

Na última década temos visto que o processo de democratização da informação tem avançado bastante, a ponto de alcançar quase que todos os cidadãos de variadas maneiras e se utilizando de diversos instrumentos e veículos, sendo que a internet tem se constituído como o principal de todos, por ser de fácil acesso e por captar as informações rapidamente, divulgando-as com igual rapidez. $\mathrm{O}$ andamento da vida social do planeta é baseado na eficácia que os meios de comunicação expressam através de sua veracidade, confiabilidade e rapidez. Instituições, empresas e até cidades inteiras têm suas atividades paralisadas se sofrem bloqueio de suas fontes e veículos de informação e comunicação. O mundo, então, não é Mundo se não tem a tecnologia necessária à projeção da informação. Ideias são incutidas, conceitos são disseminados através da informação e da comunicação. Todo um aparato social é mantido com o auxílio da ferramenta, talvez mais importante: a palavra.

Podemos afirmar, então, que a ideologia, a forma de ver o mundo e as atitudes das pessoas é estabelecida e reproduzida com base nas informações disseminadas pelos inúmeros meios de comunicação. A configuração da nossa sociedade é mantida ou transformada; as características pessoais e coletivas da Humanidade também são uma das demandas influenciadas 
por esse processo. Conceitos que determinam nossas atitudes diárias e equivocadamente naturalizadas se tornaram sutil e imperceptivelmente mutáveis. A "infância", a "família", a "juventude", a "sexualidade" já não têm o mesmo significado hoje que tinham há poucos anos. Metamorfosearamse através de discursos produzidos e veiculados pelos fenômenos da comunicação. Tornaram-se efêmeras e apressadas. Isso dá um sentimento de concretude ao que prega a ciência pós-estruturalista: culturalidade, historicidade, transformação.

Mas, na mesma medida, a informação e a comunicação podem se abater sobre determinado assunto de forma a lhe omitir reais significados ou transformar em instável algo até o momento seguro. A homossexualidade sofre essas duas consequências do processo de comunicação e de sua extrema capacidade em consolidar uma ideia.

Não julgamos necessário desdobrarmo-nos em explicações sobre a atual situação das homossexualidades em relação aos discursos que são produzidos sobre elas. A evidência de que essas identidades sofrem com o descrédito e com a inferiorização fica patente em qualquer espaço onde se dialogue sobre $o$ assunto. Mesmo em espaços ligados às lutas democráticas, como movimentos sociais, instâncias governamentais, escolas, a situação da homossexualidade é verdadeiramente deprimente. Ainda se caracterizam estes discursos por sua forma imprecisa e carregada de arcaísmos, consequentes do passado cruel vivenciado por essa identidade.

A gênese dialógica sobre a exclusão da identidade homossexual se dá quando da instituição de mecanismos discursivos, produzidos para manter a normatividade heterossexual. Esse processo acontece com base nas ideias tradicionais de organizar o mundo por um modelo de racionalidade ocidental dominante (SANTOS, 2006), que coloca em descrédito alternativas de vida possíveis de ameaçar a atual conjuntura social e política que estabelece relações de poder na atualidade.

Tal assunto foi debatido e especificado já por Michel Foucault (1988), quando diz que a evolução ao mundo capitalista exigiu a regulação da sexualidade; violentamente as identidades não heteronormativas se tornaram alvo de extinção nos discursos: "[...] pondo a origem da Idade da Repressão no século XVII; após centenas de anos de arejamento e de repressão livre, faz-se com que [a repressão moderna do sexo] coincida com o desenvolvimento do capitalismo: ela faria parte da ordem burguesa" (FOUCAULT, 1988, p. 11-12). Para isso foram escolhidas identidades e práticas que se tornaram legítimas ou não-legítimas de acordo com as necessidades do processo de evolução capitalista. Estas foram configuradas de forma a garantir a perpetuação de tal 
sistema. Dessa forma, seguindo o raciocínio de Foucault (1988), os discursos foram os instrumentos que efetivaram todo o processo de consolidação das práticas sexuais enquanto legítimas ou não; resultando na consolidação da prática sexual heterossexual como legitimamente aceita. A meta seria desestabilizar o pensamento acerca da sexualidade, infundindo um modo único de ser praticada, inicialmente através do "pensar sobre a sexualidade" e posteriormente do "praticar a sexualidade".

Denominar o sexo seria, a partir desse momento (século XVII), mais difícil e custoso. Como se, para dominá-lo no plano real, tivesse sido necessário, primeiro, reduzi-lo ao nível da linguagem, controlar sua livre circulação no discurso, bani-lo das coisas ditas e extinguir as palavras que o tornam presente de maneira demasiado sensível. (FOUCAULT, 1988, p. 23-24).

Foucault (1988) cita a homossexualidade enquanto uma das identidades perseguidas, assim como cita as formas de tentar exterminá-las pelos discursos infiltrados nas relações sociais. Vale ressaltar que os discursos comentados por Foucault (1988) não se limitam a questões negativas sobre a sexualidade. Segundo esse autor, tais discursos se caracterizam não pela "multiplicação provável dos discursos ilícitos, ou de infração" (1988, p. 22); a forma de falar do sexo tem um caráter mais abrangente e regulador:

Cumpre falar do sexo como de uma coisa que não se deve simplesmente condenar ou tolerar, mas gerir, inserir em sistemas de utilidade, regular para o bem de todos, fazer funcionar segundo um padrão ótimo. $O$ sexo não se julga apenas, administra-se. (FOUCAULT, 1988, p. 30).

Visto isso é que concordamos com Foucault e trazendo a questão dos discursos como ela se apresenta na atualidade é que refletimos um pouco sobre as formas de tentar exterminar as identidades homossexuais, mais especificamente dentro dos ambientes escolares.

Cabe-nos pensar sobre isso na medida em que a questão da homossexualidade e as relações de poder determinadas pelos discursos são, sem sombra de dúvida, interligadas, uma vez que, estando em minoria, as identidades homossexuais ao ganhar poder social constroem um novo modo de se relacionar financeira, profissional e legalmente, ameaçando a hegemonia de grupos que estão no poder, ou, simplesmente, ocupando espaços antes desconhecidos por homossexuais.

$\mathrm{Na}$ escola, estes discursos têm livre acesso, são expostos e, pior, aceitos pela comunidade escolar. Não apenas são veiculados lá, mas nascidos e alimentados pelas práticas pedagógicas e pelas atitudes inconscientes de docentes, discentes, gestores e toda a comunidade. Faz-se necessário 
empreender uma força contrária aos discursos pejorativos e homofóbicos nas instituições de ensino, utilizando-se de recursos avançados e inovadores para reconstruir significados sobre a homossexualidade, sendo a palavra o mais antigo, acessível, atingível e criativo desses recursos.

\section{REPRESENTAÇÃo DOCENTE}

Paralela a todas as problemáticas relacionadas à homossexualidade existe uma outra que segue caminhos próprios, apresenta-se mais complexa que todas as outras e ainda não encontrou suporte forte o suficiente para se insinuar nos ambientes escolares; estamos falando da questão da homossexualidade docente.

Professores e professoras homossexuais aparecem com mais frequência nos debates midiáticos do mundo inteiro; ora entre as colunas de jornais, relacionados a crimes de pedofilia, ora em discursos aparentemente científicos relacionados à influência na conduta sexual dos estudantes. Esses/as profissionais sofrem com o crescente e feroz bombardeio de informações sobre sua identidade. E como já falamos anteriormente isso tem consequências diretas na forma de reconhecer os sujeitos detentores dessa identidade. Profissionais da educação vivem um intenso dilema entre a necessidade de se expressar e de se ocultar nos espaços escolares. Ambas as posturas têm grande aceitação por parte de grupos de estudiosos da área da sexualidade, e são defendidas como estratégia de convivência pacífica entre heterossexuais e homossexuais.

Sobre esse assunto, em publicação recente da UNESCO e do MEC (JUNQUEIRA, 2009), Denilson Lopes (2009) apresenta suas reflexões sobre a questão da invisibilidade; seu artigo deixa bem claro que ele defende uma postura homossexual pautada na existência sutil e no silêncio como possibilidade de estabelecer uma convivência pacífica entre heterossexuais e homossexuais. Este autor coloca seus argumentos sobre a ideia de que as posições "intempestivas" - como ele acredita ser a forma de expressão atual dos homossexuais - sejam desnecessárias e até contrárias à paz sonhada por gays, lésbicas e travestis. Então, de que outra maneira encontrá-la senão pela iniciativa do silêncio?!

O trabalho de Lopes (2009) nos faz pensar que a exposição faz mal às relações entre heterossexuais e homossexuais; que as pessoas se sentem ofendidas ao se deparar de forma tão contundente com identidades consideradas normais, mas que na verdade de normais não têm nada. E ele propõe uma questão: 
Como seria possível, hoje então, não só uma estética, mas uma ética encarnada no desaparecimento em tempos de máxima exposição, quando o marginal, o revolucionário, o alternativo, o independente, o minoritário são glamourizados, vendidos e empacotados nas mais populares empresas de entretenimento (LOPES, 2009, p. 363).

Nossa oposição à invisibilidade proposta por Lopes (2009) é completa e absoluta; alinhamo-nos com o pensamento difundido por movimentos sociais LGBT como O Grupo Gay da Bahia (GGB), quando ele trata da visibilidade como ferramenta-chave para a reconstrução da homossexualidade enquanto uma identidade tão legítima quanto qualquer outra e que, por isso, tem o direito de ser expressa. Esse ato tem mobilizado toda a sociedade, para romper com a ideia, ainda aceita, de que ser gay ou lésbica, ou travesti, ou bissexual é sinônimo de inferioridade.

$\mathrm{Na}$ verdade, pensar a invisibilidade como recurso à comunidade homossexual é justamente uma das maneiras de se concretizar os preconceitos, ao impor a ela o refúgio, o exílio e o abandono de sua identidade. Ribeiro, Soares e Fernandes (2009), ao discutir sobre a ambientalização de professores e professoras homossexuais no espaço escolar, narram experiências de três professores e uma professora, todos homossexuais, e seus conflitos para se inserirem na escola enquanto sujeitos detentores de identidades homossexuais. As falas desses professores e professoras apontaram para questões desenvolvidas já há algum tempo por estudiosos da área. Como bem coloca os autores, a revelação da identidade homossexual abre caminho para se inferir sobre outras identidades desses profissionais, inferências estas pouco convidativas ao contato. Essa previsão exige deles uma autoinvisibilização que traz como consequência o aviso implícito nesse silêncio de que a qualquer momento, ao se revelar uma identidade sexual fora da norma heterossexual, diminua-se o respeito a esses sujeitos. A falsa identidade heterossexual ou até assexuada mantém as características necessárias a esses profissionais que tratam tão diretamente com a construção dos sujeitos - ou seja, a característica"normal","aceitável"-, até o momento em que sua homossexualidade o traia e mostre a devassidão, o pecado, a doença, a sujeira e a inferioridade inscrita na significação atual da homossexualidade.

Após ter acesso a dados tão úteis, expostos nesse último texto (RIBEIRO et al. 2009), relacionados ao ocultamento, nos espaços escolares, da identidade homossexual de professores e professoras, não podemos deixar de nos remeter à questão do nosso posicionamento político. A notória discriminação e o difícil acesso a direitos sociais de gays e lésbicas exigem 
que a escola, enquanto instituição fomentadora da igualdade e espaço de democracia, insira explícita e urgentemente em suas atividades, discussões e ações que viabilizem a equidade entre todas as identidades sexuais; essas atitudes por parte da escola pedem uma reconstrução dos significados sobre a homossexualidade e, sobretudo, sobre a educação. Essa atitude não pode ser opção de trabalho de um/a ou outro/a professor/a. A escola tem que encarnar em sua práxis o respeito ao direito de expressão. Deve vetar qualquer possibilidade de negação ou ocultação da homossexualidade. A expressão é inerente a qualquer identidade, podendo se manifestar em qualquer espaço, pertencendo a qualquer pessoa; professores e professoras não podem abrir mão desse direito.

\section{PresençAS}

Nossos resultados estão apresentados neste trabalho de forma resumida por motivo, além de outros, de seu formato de apresentação, que impossibilita uma descrição detalhada. Entretanto, nosso diário de campo contém o registro organizado, sistematizado e parcialmente analisado de todos os dados da pesquisa. Contudo, a apresentação que faremos não deixa ônus em relação à compreensão necessária dos nossos resultados.

Procurando dar conhecimento sobre o assunto que nossa primeira categoria teórica contempla: política educacional e curricular, encontramos respostas que evidenciam os dois motivos para a ausência do tema "diversidade sexual" nas escolas. O primeiro, a 'invisibilidade curricular', foi percebido em falas como a que descreveremos a seguir, de quando interrogados/as os/as professores/as sobre a possibilidade de trabalhar com o tema e os motivos da sua ausência na escola:

Acho que os termos que se usa para falar desse tema em sala de aula ainda chocam os alunos. Não se sabe muito bem o que falar nem como falar. Os professores apenas tentam diminuir o preconceito com conversas, mas falta muito pra aprender a trabalhar pedagogicamente. (MELLO, 2012).

Essa fala se torna significativa para entendermos que o crescimento das lutas e dos debates sobre a temática da diversidade atrelada à realidade escolar tem encontrado um obstáculo: o da falta de diretrizes ou recursos didáticos e pedagógicos. Os/as professores/as aprenderam a tratar didaticamente na escola com o sexo, com as doenças, com conteúdos considerados delicados para a sociedade, como aborto, gravidez, DSTs etc. Entretanto ainda existe um mecanismo que amedronta os/as 
profissionais docentes quando se fala em discutir a diversidade sexual ou a homossexualidade - esse é o da invisibilidade através do currículo.

Temos percebido cada vez mais forte a existência do mecanismo da ausência como forma de invisibilizar e manter na marginalidade as identidades aqui em debate. As identidades não heteronormativas ainda são legal e socialmente consideradas como desnecessárias e indesejadas na constituição de uma nação. Mesmo estando presentes de forma mais aberta e visível no nosso dia a dia, essas identidades têm a ausência curricular como justificativa de discriminação e de permanência na marginalidade e na exclusão.

A exclusão social das identidades não-heteronormativas se ampara pela forma como elas são encaradas em várias esferas, como a legal, por exemplo, que as punem negando seus direitos. Um desses, o de a identidade ser respeitada e reconhecida como legítima, necessita do auxílio da Educação para ser concretizado, mas não tem suporte regulamentado em nenhuma lei específica para isso, e permanece excluído das atividades escolares, como nos mostrou a fala da professora de Caruaru.

Como já indicamos, além desse motivo, existe o dos valores e normas pessoais, que mantêm a ausência do tema da diversidade sexual nos espaços escolares. Em nosso estudo os/as profissionais questionados/as não deram nenhuma indicação de oposição ao trabalho com essa temática por esse motivo. Infelizmente não pudemos constatar se suas respostas apenas correspondem a uma exigência de posicionamento progressista que tem tomado conta dos/as profissionais da educação; mas com certeza há ao menos conhecimento da necessidade de tratar o tema da diversidade sexual nos espaços educativos.

De toda forma, informaram que tratar esse tema envolve questões ligadas a critérios religiosos e morais, por isso seu desempenho como profissional se encontra em déficit, por não saber lidar com o conflito entre o tema e esses critérios que se opõem a ele, como, por exemplo, a religião e a heteronormatividade. Como diz uma das professoras quando questionadas sobre o sentimento de preparo para lidar com uma situação didática envolvendo o tema da diversidade:"Não me sinto preparada, pois é um tema que trata de dimensões morais, religiosas, sociais, sendo assim, um tema que exige preparação aprofundada." (BRONNER, 2012).

Essa fala deixa claro que, mesmo que compartilhem do desejo de trabalhar o tema em questão na sua dinâmica educacional, os/as profissionais se sentem encurralados por questões que até hoje vêm moldando a sociedade em que se vive. Uma dessas questões é a religião; outra, a procura por uma heterossexualidade naturalmente nascida junto com nosso corpo biológico. 
Esses/as profissionais se mostram vítimas da lógica de valores pessoais vigente quando se trata de questões sexuais.

Ao longo das respostas dadas aos questionários, várias foram as falas que ilustraram os motivos da ausência da "diversidade sexual" nos espaços escolares. Não teríamos possibilidade de mostrar esses dados em sua completude nem nos acorre apresentá-los quantitativamente, uma vez que optamos por fazer uma análise qualitativa. Mas vale salientar que alguns sujeitos, quando ignoraram algumas questões básicas ou defenderam outras, deram-nos informações que se aproximaram de um ou de outro motivo indicado na categoria teórica que temos debatido no momento, como, por exemplo, professores/as que defenderam o uso de ensinamentos religiosos para trabalhar a questão da homossexualidade, ou dos/as que não souberam dar nenhuma fonte de referência teórica ou curricular sobre a questão (dados presentes em nosso diário de campo). Essas respostas nos indicam a maneira latente com que tanto a invisibilidade curricular quanto os valores e normas pessoais têm regido as práticas educativas no sentido de orientar sobre a diversidade sexual.

Em relação a falas que nos dessem informações sobre os discursos homofóbicos, não reconhecemos em nenhum questionário falas que indicassem essa perspectiva por parte dos/as professores/as entrevistados/as. Entretanto, algumas falas se aproximam de conceitos que fomentam a discriminação à diversidade sexual. Assim, optamos por caracterizar essas falas não como homofóbicas, mas como falas que ignoram os debates acerca do tema.

As falas a seguir nos chamam a atenção para o fato de que elas se mostram pouco esclarecidas sobre a situação da diversidade sexual e da homossexualidade. Ao serem interrogadas/os sobre o motivo da sexualidade, os/as professores/as indicaram os seguintes motivos:

Escolhas, traumas (MEZES, 2012).

Opção (MEZES, 2012).

Eu acho que por opção (BRONNER, 2012).

Distúrbios genéticos (BRONNER, 2012).

Já em relação a uma conduta frente à presença homossexual entre os/ as estudantes, uma das respostas nos chamou a atenção. Enquanto que os/as demais sujeitos de nossa pesquisa mostraram inclinação para um tratamento respeitoso e pautado no diálogo e na não discriminação, uma das respostas se colocou claramente contra a expressão dessa criança. À questão"que atitude, frente à sua sexualidade, o/a professor/a deve ter com a criança que aparenta ser homossexual?", esse/a participante respondeu: "Respeitar o seu jeito de ser, mas repreender o seu modo de agir." (SILVA, 2012). 
Essas posições estão conjugadas a outras de cunho pessoal e de valores morais; mas percebemos que principalmente por falta de esclarecimento sobre a significação da diversidade sexual e das homossexualidades os discursos preconceituosos ainda têm espaço junto à sociedade.

Mais uma vez as ausências determinam o rumo do pensamento sobre o tema da diversidade. Ausência curricular e política, agora ausência de esclarecimento e de conhecimento transformam uma coisa normal, como as diferentes condutas sexuais, em coisa diversa, diferente. E essa diferença da normatividade heterossexual transforma pessoas em seres distintos dos que agem conforme a sua "natureza sexual". Essa naturalização insere milhões de pessoas em espaços periféricos e desprivilegiados de várias instâncias estatais.

Já sobre as considerações acerca da homossexualidade docente, os/ as professores/as sujeitos de nossa pesquisa nenhuma vez demonstraram atitude de reprovação ou de discriminação. Entretanto mais uma vez algumas impressões nos chamaram a atenção sobre certa resistência de expressão ou à possibilidade de assumirem sua sexualidade no seu espaço de trabalho. Todos/as foram muito delicados/as em deixar claro que essa questão é muito polêmica e deixa dúvidas sobre que condutas devem ser consideradas legítimas. Algumas falas se interessam em pensar uma conduta moldada a partir da discrição e do ocultamento das características consideradas típicas da homossexualidade, distanciando assim a vida profissional da vida pessoal. Outras se interessam em considerar essa possibilidade enquanto um ato de emergência de direitos, independente do espaço profissional em que estejam.

Entre as respostas dadas pelos/as professores/as, destacamos as que eles/as respondem sobre sua posição em relação a profissionais que assumem sua homossexualidade.

Toda e qualquer pessoa é protegida legalmente para assumir suas opções. (MEZES, 2012).

Correto, o pessoal é de cada um e isso não deve interferir na vida profissional. (MEZES, 2012).

Uma atitude de coragem e respeito a si próprio. (MELLO, 2012).

Primeiro uma questão de coragem, mas, acima de tudo uma prova de personalidade e de coerência com a questão dos valores e do respeito com ele mesmo. Porém, todos devemos manter o respeito por si próprio independente da sexualidade, pois afinal de contas, somos vistos como exemplo, referencial. (COSTA, 2012).

Ótimo, no dia em que perdermos a hipocrisia vamos ser mais felizes. (BRONNER, 2012).

Legal, cada um tem que se aceitar e ser aceito como é. (BRONNER, 2012). 


\section{Conclusões}

Algumas dúvidas são capazes de consolidar certezas na ideologia das pessoas. Já algumas ideias são construídas sobre o alicerce de comprovadas inexistências; a inexistência de uma natureza heterossexual, por exemplo. Essa ideia conviveu durante toda a história da Humanidade com a sua contradição, e cada vez mais as provas de ser a heterossexualidade um fator ideal para a sociedade têm sido experimentadas qualitativa e quantitativamente. Esse fato mais do que provado não nos deixa tão preocupados quanto a percepção de que as diversas formas de violência sofridas pelas pessoas que não se comportam conforme tal norma têm crescido amparadas pelos silêncios que se infiltraram globalmente em todos os espaços de convivência da nossa sociedade.

Assim é que nosso trabalho expôs as ausências sobre a diversidade sexual no contexto da Educação. Esses silêncios foram ilustrados por falas de docentes atuantes da região do Agreste de Pernambuco; dessa forma consideramos que são fruto de um processo amplo de consolidação da inexistência da diversidade sexual e das homossexualidades. As ausências que foram apresentadas e discutidas aqui funcionam como instrumento de exclusão ativa de milhares de cidadãos e cidadãs que co-habitam com outros não discriminados por sua orientação sexual num mesmo espaço geográfico.

Percebemos facilmente a maneira como as falas nos direcionaram a um ponto em comum como o resultado desse processo de exclusão e de invisibilidade: a negação da possibilidade de ter a diversidade sexual como legitimamente instituída na sociedade e do convívio pacífico entre as diversas formas de viver a sexualidade. Não dizemos que as/os docentes servem a esse fim, mas repetimos: as posições ideológicas dos docentes são fruto das ausências, seja nas políticas curriculares ou nos discursos e na linguagem, que determinam uma cisão entre as condutas sexualmente aceitas e não aceitas.

Fazendo considerações sobre o que nos mostrou nosso trabalho de investigação, pretendemos fazer uma verdadeira apologia à diversidade sexual, no sentido mais amplo em que possa ser entendida: a diversidade não está na especificidade de um grupo diferenciado da norma heterossexual, reduzida à distinção entre heterossexualidade e homossexualidade. Ela abarca as particularidades de cada ser humano enquanto detentor de uma identidade e uma conduta sexual ímpar, seja heterossexual ou homossexual. A diversidade está menos ligada à especificação anatômica e física e suas performances do que ao reconhecimento da plasticidade sexual de cada ser humano. 
A diversidade está presente também no quadro de pessoas heterossexuais, sabendo-se que cada um vive sua sexualidade de maneira particular e diferenciada, assim como no quadro de pessoas homossexuais pelo mesmo motivo. Acreditamos que o prolongado período de engessamento fez com que as condutas sexuais diversificadas não se relacionassem às identidades heterossexuais; que essas foram por esse motivo consideradas homogêneas, iguais, não levavam em consideração estímulos e prazeres diversos. Mas hoje se conhece mais sobre a dinâmica das sexualidades e é possível acreditar na diversidade sexual como a verdadeira natureza sexual humana.

Assim, a escola e a Educação têm a tarefa de acreditar que aderindo ao debate da comunidade LGBT e se apropriando de suas lutas e de suas metas não só estarão contribuindo para uma causa que trará benefícios para uma comunidade específica, mas para a nossa condição humana. A Educação foi escolhida para aprofundar e aperfeiçoar o pensamento e as práticas que possam elevar nossa condição de seres humanos e sociais, individuais e coletivos.

A região do Agreste pernambucano avança no sentido de, agora, ter a possibilidade de conhecer as bases que instituem a discriminação e as diferenças de direitos baseadas nas particularidades sexuais. Esse é o momento de construir meios e instrumentos que possibilitem e facilitem a luta contra essas bases.

Nesse sentido, são fundamentais os movimentos sociais; a consciência sobre lideranças políticas, suas posições ideológicas e suas defesas; o avanço de leis de enfrentamento à violência e de punição a agressores/as; e a consolidação de garantias civis que possam algumas vezes ignorar o fato de ser homossexual (como no caso, por exemplo, do debate sobre casamento gay), e outras vezes levar em consideração a situação vulnerável a que estão sujeitos/as esses mesmos indivíduos, a exemplo da evasão escolar de identidades sexuais que sofrem com a discriminação.

Ainda devemos nós, profissionais da Educação, nos comprometer em fundar um pensamento novo sobre a questão da diversidade sexual, aproximando-nos dos discursos e colocando em prática as estratégias ao nosso alcance para continuar a dinâmica do mundo de uma maneira diferente da vivenciada até agora, sem preconceitos, discriminação, exclusão, e sim com esclarecimento, acolhimento e equidade. 


\section{GENDER DISPUTES: ABSENCE AND PRESENCE OF LGBT DEMAND IN SCHOOL}

AвSTRACT: This paper presents the LGBT subject and its demands on education as the central theme. It aims to point out the absences, as well as the presence in the educational field of gender issues that are important and object to dispute for LGBT citizenship. It brings the research experience of 5 cities in Agreste of Pernambuco, trying to identify such absences and presences. It adopted a qualitative research methodology, and, as a strategy of data collect, it made use of interviews and semistructured questionnaires. The results point out the alignment of school's experiences with our theoretical premises regarding educational policies, school practices and teaching representation. Nevertheless, important and original information emerge from the particularities of each analyzed context.

KEYWORDS: School. Gender. Political disputes. Invisibility and LGBT representation

\section{EL GÉNERO EN DISPUTA: AUSENCIAS Y PRESENCIAS DE LA DEMANDA LGBT EN LA ESCUELA}

RESUMEN: Este artículo presenta la cuestión LGBT y sus demandas como tema central de la educación. El objetivo es señalar las ausencias, así como las presencias de temas relacionados al género en el campo educativo. Esos temas son apreciados y objeto de disputa para los ciudadanos LGBT. Aporta la experiencia de una investigación desarrollada en cinco municipios del Agreste Pernambuco, que intenta identificar tales ausencias y presencias. Se adoptó la metodología de investigación cualitativa y, como estrategia de recolección de datos, se hizo uso de entrevistas semiestructuradas y cuestionarios. Los resultados indican que, si por un lado, en lo que se refiere a las políticas educativas, prácticas escolares y representación docente, las experiencias escolares y nuestras premisas teóricas están alineadas. Por otro lado, también motivan el surgimiento de informaciones importantes y originales nacidas de las particularidades de cada contexto analizado.

PalABRAs-CLAVE: Escuela. Género. Disputas políticas. Invisibilidad y representación LGBT.

\section{REFERÊNCIAS}

COLLING, L. Que os outros sejam o normal: tensões entre movimento LGBT e ativismo queer. Salvador: EDUFBA. 2015.

BARDIN, L. Análise de Conteúdo. Lisboa: Relógio D'água Editores, 2001.

BRASIL. Ministério da Educação. Secretaria de Educação Fundamental. Parâmetros Curriculares Nacionais: Temas Transversais. Brasília: MEC/SEF, 1998. 
BRASIL. Presidência da República. Casa Civil. Subchefia para assuntos jurídicos. Lei $n^{\circ}$ 13.005, de 25 de junho de 2014. Aprova o Plano Nacional de Educação. Diário Oficial da União, Poder Executivo, Brasília, DF, 26 jun. 2014a. Seção 1, p.1.

BRASIL. Ministério da Educação. Secretaria de Articulação com os Sistemas de Ensino. Planejando a próxima década: Conhecendo as 20 metas do Plano Nacional de Educação. Brasília: (MEC/SASE), 2014b.

BRONNER, B. B. Bronner: depoimento [mar. 2012]. Entrevistador: Rafael Vieira. Caruaru: UFPE, 2012. Mídia digital. Entrevista concedida ao Projeto Diversidade(s) e Ausências: O debate do Movimento LGBT e suas repercussões no corpo docente de escolas públicas do agreste de Pernambuco.

COSTA, J. J. Costa: depoimento [mar. 2012]. Entrevistador: Rafael Vieira. Caruaru: UFPE, 2012. Mídia digital. Entrevista concedida ao Projeto Diversidade(s) e Ausências: O debate do Movimento LGBT e suas repercussões no corpo docente de escolas públicas do agreste de Pernambuco.

FOUCAULT, M. História da sexualidade I: a vontade de saber. Rio de Janeiro: Edições Graal, 1988.

FURLANI, J. Políticas identitárias na educação sexual. In: GROSSI, M. P. et al. (Org.) Movimentos sociais, Educação e Sexualidades. Rio de Janeiro: Garamond, 2005.

JUNQUEIRA, R. D. (Org.). Diversidade sexual na educação: problematizações sobre homofobia nas escolas. Brasília: MEC (Secretaria de Educação Continuada, Alfabetização e Diversidade); UNESCO, 2009.

LOPES, D. Por uma nova invisibilidade. In: JUNQUEIRA, R. D. (Org.). Diversidade sexual na educação: problematizações sobre homofobia nas escolas. Brasília: MEC (Secretaria de Educação Continuada, Alfabetização e Diversidade); UNESCO, 2009.

MELLO, J. J. Mello: depoimento [mar. 2012]. Entrevistador: Rafael Vieira. Caruaru: UFPE, 2012. Mídia digital. Entrevista concedida ao Projeto Diversidade(s) e Ausências: O debate do Movimento LGBT e suas repercussões no corpo docente de escolas públicas do agreste de Pernambuco.

MEZES, I. I. Mezes: depoimento [mar. 2012]. Entrevistador: Rafael Vieira. Caruaru: UFPE, 2012. Mídia digital. Entrevista concedida ao Projeto Diversidade(s) e Ausências: O debate do Movimento LGBT e suas repercussões no corpo docente de escolas públicas do agreste de Pernambuco.

RIBEIRO, P. R. et al. Ambientalização de professores e professoras homossexuais no espaço escolar. In: JUNQUEIRA, R. D. (Org.). Diversidade sexual na educação: problematizações sobre homofobia nas escolas. Brasília: MEC (Secretaria de Educação Continuada, Alfabetização e Diversidade); UNESCO, 2009.

SANTOS, B. S. A Gramática do Tempo:Para umanova cultura política. São Paulo: Cortez, 2006. 
SILVA, C. C. Silva: depoimento [mar. 2012]. Entrevistador: Rafael Vieira. Caruaru: UFPE, 2012. Mídia digital. Entrevista concedida ao Projeto Diversidade(s) e Ausências: O debate do Movimento LGBT e suas repercussões no corpo docente de escolas públicas do agreste de Pernambuco.

Rafael Lima Vieira: Doutorando em Estudos da Criança no Instituto de Educação da Universidade do Minho. Mestre em Educação Contemporânea pela UFPE.

E-mail:dr.rafael.lima.vieira@gmail.com

Allene Carvalho Lage: Professora Associada da Universidade Federal de Pernambuco / Centro Acadêmico do Asreste. Professora do Curso de Pedagogia do Núcleo de Formação Docente. Professora Permanente do Mestrado em Educação Contemporânea do PPGEDUC/ CAA. Professora Permanente do Mestrado em Direitos Humanos do PPGDH/CAC. Coordenadora do Observatório dos Movimentos Sociais na América Latina e do Pré-Acadêmico SuperAção.

E-mail: allenelage@yahoo.com.br 